\title{
A Nexus model of cellular transition in cancer
}

\author{
Mukesh Yadav ${ }^{1 *}$, Payal Chatterjee ${ }^{1,2}$, Simran Tolani ${ }^{1}$, Jaya Kulkarni ${ }^{1}$, Meenakshi Mulye $^{1}$, Namrata Chauhan ${ }^{1}$, \\ Aditi Sakhi ${ }^{1}$ and Sakshi Gorey ${ }^{1}$
}

\begin{abstract}
The exact cause of cancer is one of the most immutable medical questions of the century. Cancer as an evolutionary disease must have a purpose and understanding the purpose is more important than decoding the cause. The model of cancer proposed herein, provides a link between the cellular biochemistry and cellular genetics of cancer evolution. We thus call this model as the "Nexus model" of cancer. The Nexus model is an effort to identify the most apparent route to the disease. We have tried to utilize existing cancer literature to identify the most plausible causes of cellular transition in cancer, where the primary cancer-causing agents (physical, chemical or biological) act as inducing factors to produce cellular impeders. These cellular impeders are further linked to the Nexus. The Nexus then generates codes for epigenetics and genetics in cancer development.
\end{abstract}

Keywords: Cancer, The Nexus model, Biochemical stress, Epigenetics, Mutations, Genetics

\section{Background}

Cancer research has made an outstanding progress to identify and tackle the probable causes of the disease, which stands to be unique with respect to the organs affected and the genetic makeup of the individuals. The disease has been explored for its exact mechanism from all possible scales of molecular biology to deep insights of genetics. Various theories have covered long range of possible causes of cancer viz. cellular fluids, cellular events, tissue level modifications and even genetic aberrations [1-9]. Despite the fact that, different types of cancer differ in their primary causes, linked tissues, progression patterns and converging pathophysiology, there appears many overlapping features in common. These common features are accelerated cell division, altered, rewired and escalated metabolic pathways, $[10$, 11] distorted shape, abnormal nucleus, [12] inefficient mitochondria, acidic intracellular environment, contact inhibition, loss of apoptosis, angiogenesis, metastasis and many others. These common and overlapping features

\footnotetext{
*Correspondence: mukesh@softvision.co.in; mukesh17585@gmail.com

${ }^{1}$ Department of Pharmaceutical Sciences, Softvision College

and Research Institute, Vijaynagar, Indore, MP 452010, India

Full list of author information is available at the end of the article
}

indicate an unidentified underlying common cause, which is although obvious, need some reflection.

In the last decade, carcinogenesis has been consistently proven to be an evolutionary process and thus it must have a purposeful cause [13]. This evolutionary paradigm begins with cellular environment, travels through biochemistry and finally codes out in terms of its genetics. Here, cellular biochemistry plays an amalgamating role between environment and genetics. In order to identify the exact cause and mechanism of cancer, the purpose (why) is more important than the cause (how). Present work connects the well-known and lesser known findings in cancer research to highlight the underlying transition route through which a normal and healthy cell supposedly transforms to its cancerous phenotype.

\section{Methodology}

Cancer research has been exploring all possible dimensions to identify the exact causes of cancer. Present cancer hypothesis, the Nexus model, is an effort to encircle primary cancer causes, cellular biochemistry, epigenetics and genetics in a single model where each of them acts as a node in transition route. The Nexus model explains the purpose behind cancer evolution and so as the cause. 


\section{The Nexus model}

This model proposes that the probable transition route opens with the primary inducers (established primary causes) such as physical, chemical, biological and lifestyle related causes (Fig. 1). Such primary inducers then interact with the cellular biochemical pathways and generate reactive oxygen and nitrogen species (RONS) along with other free radicals, also known as cellular impeders (Fig. 1). The RONS, free radicals and viruses can also bring random genetic aberrations, which then generates structurally and functionally altered regulatory molecules (biomolecules) involved in metabolic pathways [14-16]. The interference of the cellular impeders thus results in the accumulation of initial substrates, intermediates or partial pathway products. Such an accumulation of the biologically insignificant metabolites congest cellular traffic thereby leading to a cellular environment that hampers the breakdown of normal metabolic pathways. This further develops an overload of residual metabolites in the cellular environment. Such a scenario results in the loss of intercellular signaling in a tissue and ultimately cause prolonged cellular biochemical stress that continues through many cell cycles, and eventually alters the cellular microenvironment. Such a complete alteration of the cellular microenvironment and the loss of intercellular signaling then creates perfect platform to initiate chain of events responsible for epigenetic and genetic changes [17]. Such events cause prolonged biochemical stress, thereby inducing considerable changes in stressed cells and marking the beginning of cellular events leading to cancer. Such events are hereby called as the Nexus. Initially, such mutations are random and result into expression of biomolecules which may either add to or reduce the biochemical stress (the Nexus) [18], better known as positive or negative cellular feedback. While the "positive feedback" refers to the survival of the mutations that reduces cellular stress, "negative feedback" refers to the mutations that might contribute to the increase of substrates, intermediates and partial products. The positive feedback is evidently repeated in the forthcoming cycles featuring mutational selection, resulting into newly evolved genetic machinery powered by such selective mutations $[13,18,19]$. On the other hand, such mutations are also capable of consuming residual metabolites via rewired metabolic pathways and have high rates of proliferation and turn out to be cancerous [20-27]. Over time, survival and accumulation of selective mutations which aid to positive feedback result in cancer phenotype (cancer evolution) of a healthy cell. The word 'Nexus' justifies the role of biochemical stress as the junction where strings originated from primary inducers further travel to epigenetics and genetics in cancer evolution.

In order to substantiate the Nexus Model, experimental and established evidences have been composed below under Phase I, Phase II and Phase III.

\section{Phase I: primary inducers and cellular impeders}

Oxidative stress is a condition which results due to the production of oxidative radicals, mostly reactive oxygen species (ROS) and reactive nitrogen species (RNS) that exceeds the quenching limit of cells [28]. RONS can be generated by a number of inflammatory reactions, physical and chemical factors [28-30] (Fig. 2). It is an established fact that lifestyle factors, which include cigarette smoking, sun exposure, workplace, diet etc., affect the chances of acquiring cancer [31, 32].

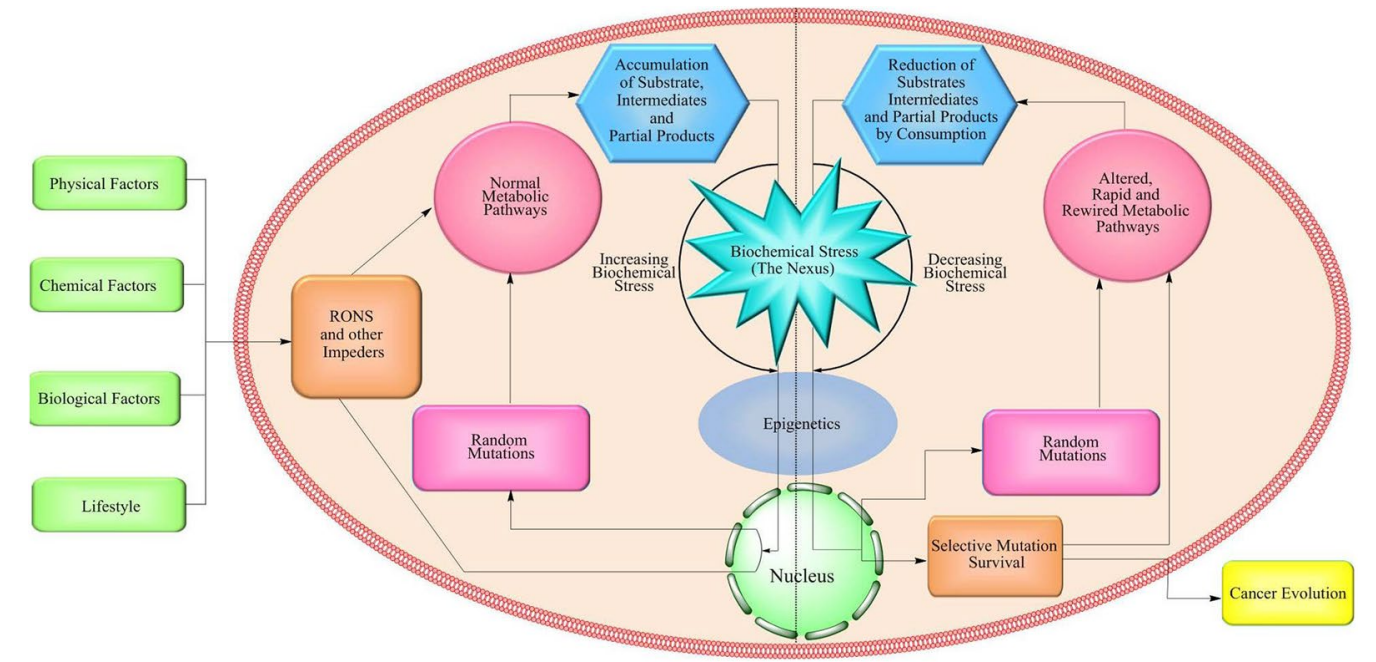

Fig. 1 The overall diagram for the Nexus model representing the most probable transition route in cancer evolution 


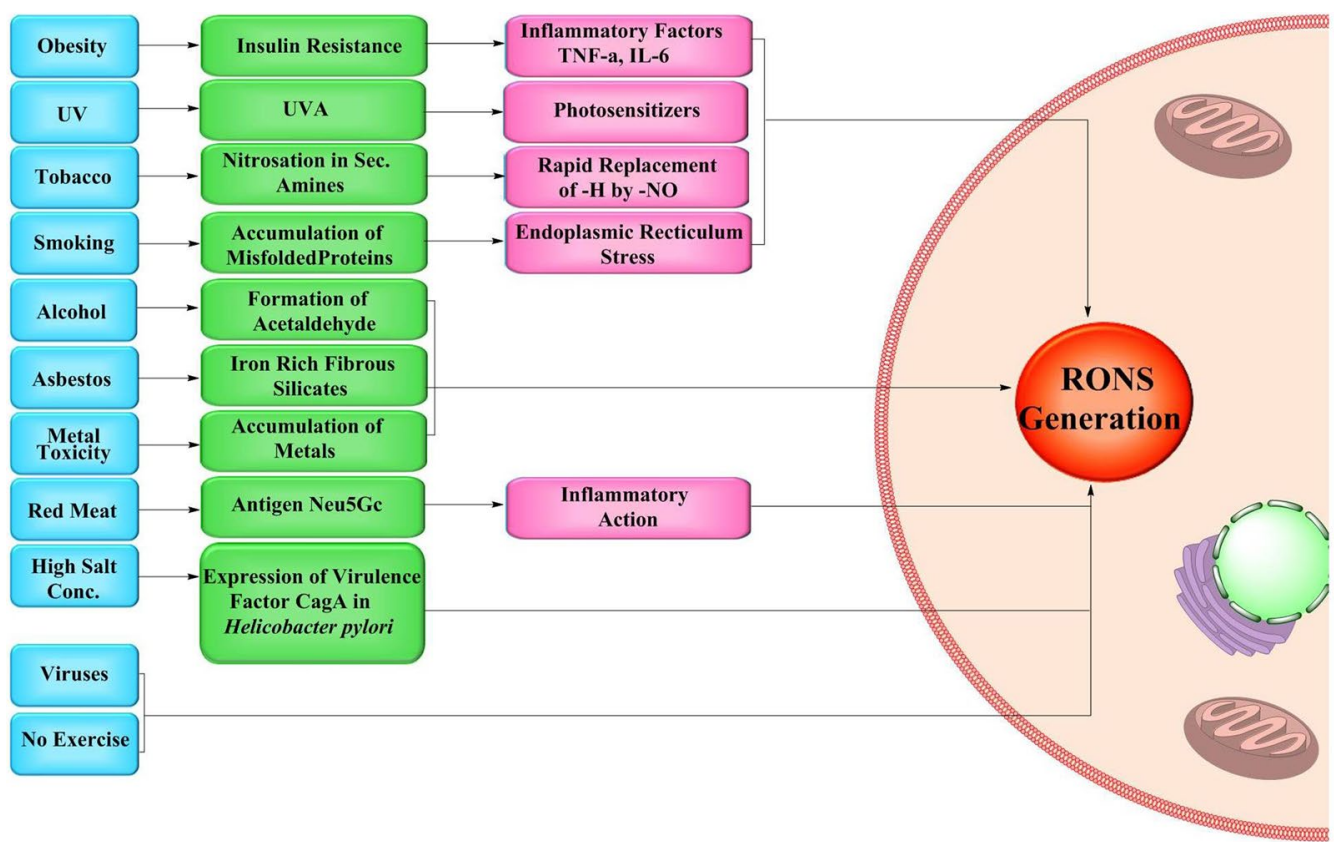

Fig. 2 Phase I (The Nexus model): Primary cancer causes (physical, chemical, biological and lifestyle) and their sequential products to end up in form of RONS

According to the National Cancer Institute, obesity has been found to be prominently associated with the risk of cancer, wherein the United States alone, in 2012, 28,000 newer cancer cases in men and 72,000 newer cases in women were linked to obesity and being overweight [33]. Various factors released by the adipose tissues result in insulin resistance and consequent production of proinflammatory factors like tumor necrosis factor- $\alpha$ (TNF$\alpha$ ), interleukin-6 (IL-6) and cytokines which end up in unusual production of ROS [34, 35]. Another factor is UV radiation that has a prominent role in causing skin cancer [36]. Most of the Ultra Violet (UVA) energy is taken by the photosensitizers in the cells which are believed to generate ROS [37]. Tobacco, cigarette smoke, alcohol, naturally occurring fibrous substance-asbestos and metal toxicity are some chemical factors which are found to be responsible for the production of RONS. Tobacco contains nicotine and structurally similar alkaloids consisting of secondary and tertiary amines which react with nitrite forming nitrosamines [38]. In case of secondary amines, nitrosation is an exceptionally fast process, in which $-\mathrm{H}$ atom attached to nitrogen is replaced by $-\mathrm{NO}$ $[39,40]$. The - NO group being a potential reactive species causes oxidative stress [41]. Exposures to smoke produced by cigarettes can be blamed for the oxidative stress as it persuades the aggregation of misfolded proteins and endoplasmic reticulum (ER) stress and consequently enhances the production of ROS [42-46]. Ethyl alcohol is converted into acetaldehyde in the body which is a budding cause of ROS production in the cells [47, 48]. Asbestos fibers are known to induce the cells to produce ROS due to the iron present on the fibrous silicates $[49,50]$. Exposure to lethal waste sites, mines and construction sites may also subject the workers to high intensity metal toxicity of mercury, lead, arsenic etc. [51, 52]. Accumulation of these metals can then lead to the generation of ROS in cells.

Red meat, high salt consumption, viral infections and physical inactivity encompass the biological factors. Antibodies are produced in response to Glycolylneuraminic acid [Neu5Gc], which acts as an antigen to the body, present in red meat. This interaction results in ignition of inflammatory cells thus producing ROS [53]. High salt consumption is also found to be a potential cause of ROS production [54]. The increased salt concentrations alter the expression of virulence factor CagA (cytotoxinassociated gene A) in Helicobacter pylori strain 26695, which is a highly acknowledged factor for cancer [55]. The infections due to Human papillomavirus (HPV) cause oxidative stress which in turn damage the cell DNA $[56,57]$. Exercise is found to decrease the ROS production in body [58].

The above discussed factors summarize how physical, chemical, biological and lifestyle related factors, termed as primary inducers (primary causes) generate RONS and other cellular impeders that hamper cellular metabolic 
pathways. Such interference then causes accumulation of cellular substrates that eventually converge to forcibly induce biochemical stress thereby facilitating the evolution of cancer. The diagrammatic illustration of the same has been provided in Fig. 2.

\section{Phase II: development of biochemical stress (The Nexus)}

Generation of reactive oxygen and nitrogen species (RONS) in the cells cause havoc in the normal functioning of enzymes and other biomolecules participating in various metabolic pathways [32]. At normal levels of RONS, the combat mechanisms are capable enough to maintain homeostasis inside cells, but when their concentration exceeds the threshold level, they impede the normal functioning inside the cell. High concentration of RONS interferes or reacts to cause delay, halt or even total loss in integrated framework of metabolic pathways $[59,60]$. As in glycolysis, the elevated concentration of RONS oxidizes and thus inactivates pyruvate kinase monomer 2 (PKM2) which is responsible for the conversion of phosphoenol pyruvate (PEP) to pyruvate [54]. Similarly, high levels of RONS regulate the HypoxiaInducible Factor-1 (HIF1) to create hypoxic conditions, which is one of the most common features recorded in almost all type of cancer cells [61]. The HIF modulates the activity of pyruvate dehydrogenase kinase 1 (PDK1) thereby restricting the activity of pyruvate dehydrogenase $(\mathrm{PDH})$ which prevents the conversion of pyruvate into acetyl $\mathrm{CoA}$, hence cause hindrance in the tricarboxylic acid cycle (TCA) [62-64]. Obstruction in the TCA cycle greatly reduces the production of ATP via electron transport chain (ETC) [62]. To maintain the redox homeostasis, glycolysis adopts to pentose phosphate pathway (PPP) which is the principal pathway for de novo synthesis of nucleotides and this shunting of pathway generates excess of nucleotides [63]. Generation of excess nucleotides through PPP pathway causes substrate accumulation in cytoplasm. Generation of excess nucleotides through PPP pathway causes substrate accumulation in cytoplasm. Partial or complete obstruction of glycolysis [65] leads to the accumulation of substrates which were supposed to be consumed under normal conditions [66]. As all the metabolic pathways are interdependent [67], it is safe to say that hindrance in a single pathway leads to the upheaval in the other linked or parallel pathways.

The HIF-1 also triggers the activity of hypoxia inducible factor 2 (HIF-2) which causes amassing of lipids in the form of droplets [68] and simultaneous loss of expression of Von Hippel-Lindau gene (VHL) [69]. The loss of VHL expression further leads to the reduced expression of $\beta$-oxidation genes causing the curtailment of the $\beta$-oxidation pathway [70]. The reduction in the pathway eventually results in the accumulation of lipids.
Nevertheless, de novo lipogenesis continues by using other carbon sources such as acetate and glutamine. The de novo synthesis is mediated by an increased level of fatty acid synthase (FASN) [71, 72].

Apart from the discussed routes that affect the biochemical pathways, RONS can cause direct damage to the DNA thereby causing random mutations [73]. These random mutations may occur in the genes that code the enzymes involved in the cellular metabolism and again lead to the disruption of these pathways, ultimately causing accumulation and biochemical stress. One such example is of isocitrate dehydrogenase (IDH) mutation. IDH is an enzyme which catalyzes conversion of isocitrate into $\alpha$-ketoglutarate [74] and provides defense against oxidative insults. Genetic alteration in the IDH gene results in the alteration of its enzymatic activity. This mutated form of the enzyme catalyzes the conversion of $\alpha$-ketoglutarate into 2 hydroxyglutarate (2-HG) which is a well-known oncometabolite [75, 76]. High concentration of the 2-HG thereby results in abnormal DNA hypermethylation in cells [77].

Another metabolite that is involved in creating the biochemical stress (Nexus) is the enzyme fumarate hydratase (FH). The RONS guided mutations inactivate $\mathrm{FH}$, which leads to the blockage of TCA cycle [78, 79]. It has two possible consequences; first, it causes accumulation of fumarate and succinate leading to biochemical stress; second, the accumulated fumarate reacts with reduced glutathione (GSH) producing succinated glutathione which is considered to be an oncometabolite [78]. This oncometabolite is further degraded by glutathione reductase releasing GSH which then combines with fumarate in an aborting manner consuming NADPH, ultimately obstructing RONS detoxifying potential of the mitochondria and thereby increasing the RONS generation [79]. Eventually, it leads to substrate accumulation and hence elevated biochemical stress (The Nexus) [80].

It can be deduced from the above-discussed facts that high RONS concentration resulting from primary inducers can, directly and indirectly, affect the normal cellular metabolic pathways. Any type of delays, layoffs or outright loss in any of the metabolic pathways results in the accumulation of substrates, intermediates and partial products. Accumulation of these components then enhances cellular traffic resulting into an overflowing abundance of such products inside the cytoplasm. Under such a condition where nutrients are no more consumed efficiently, the machinery of bioenergetics (ATP) starts to shutdown and the futile intermediates and partial products simultaneously increase the cellular traffic to generate biochemical stress (The Nexus). The prolonged biochemical stress cuts off the intercellular signaling in the affected tissues thereby bringing the cells 
into isolation. Cellular isolation and long term biochemical stress can be considered as the perfect conditions to stimulate epigenetics followed by genetic evolution. The above enlisted events can be considered as phase II of cellular transition in cancer described in Fig. 3.

\section{Phase III: epigenetics to genetic evolution \\ Biochemical stress to epigenetics}

Long term biochemical stress and interrupted intercellular signals in linked tissues create a new microenvironment which further acts as a driving signal that prepares cells for genetic evolution for biochemical negotiation. These driving signals are epigenetic changes which result in abnormal gene functions and aberrant patterns of gene expression and are usually observed in all types of cancer. Growing evidences suggest that the acquired epigenetic abnormalities interact with genetic alterations over time to cause dysregulation in the routine functioning of cells [81]. Few of the supportive findings have been produced and discussed below which collectively explain direct or indirect effect of RONS and consequent biochemical stress on cellular epigenetics and genetics.

Epigenetics involves endowment of instructions based on the expression of genes. The major modifications that basically comprise epigenetic changes are methylation, acetylation and phosphorylation which results in post translational histone modifications [82].
The prolonged exposure of the tissues to this RONS driven biochemical stress (The Nexus) and other environmental factors bring about epigenetic changes which marks the initiation of phase III in cellular transition. The stressful environment then generates several types of responses to combat the stress, most of which lead to epigenetic alterations. It is known that oxidative stress causes accumulation of unfolded proteins in ER, activating unfolded protein response (UFR) by altering the levels of molecular chaperone GRP78/BiP (78 kDa glucose-regulated protein/binding immunoglobulin protein), a master regulator of ER functions and contributor of tumor cell survival and growth [83, 84].

Stress proteins like heat shock proteins mediate an increase in chaperone protein activity which enhances protein folding capacity, thus counteracting stress and promoting cell survival [85]. DNA lesions caused as a result of oxidative stress are genotoxic and also prompt genetic mutations [86]. RONS have also found to be interfering with the cell death mechanisms, either acting as an anti-senescence agent or through the specific stimulation of AIF (apoptosis-inducing factor). It helps in suppressing apoptosis and therefore maintains the phenotypic transformation of cancer cells [87]. A recent study has showed that various oxidized products (dimethyl and methionine sulfoxide) may accumulate in the cytosol during the initial stages of carcinogenesis and

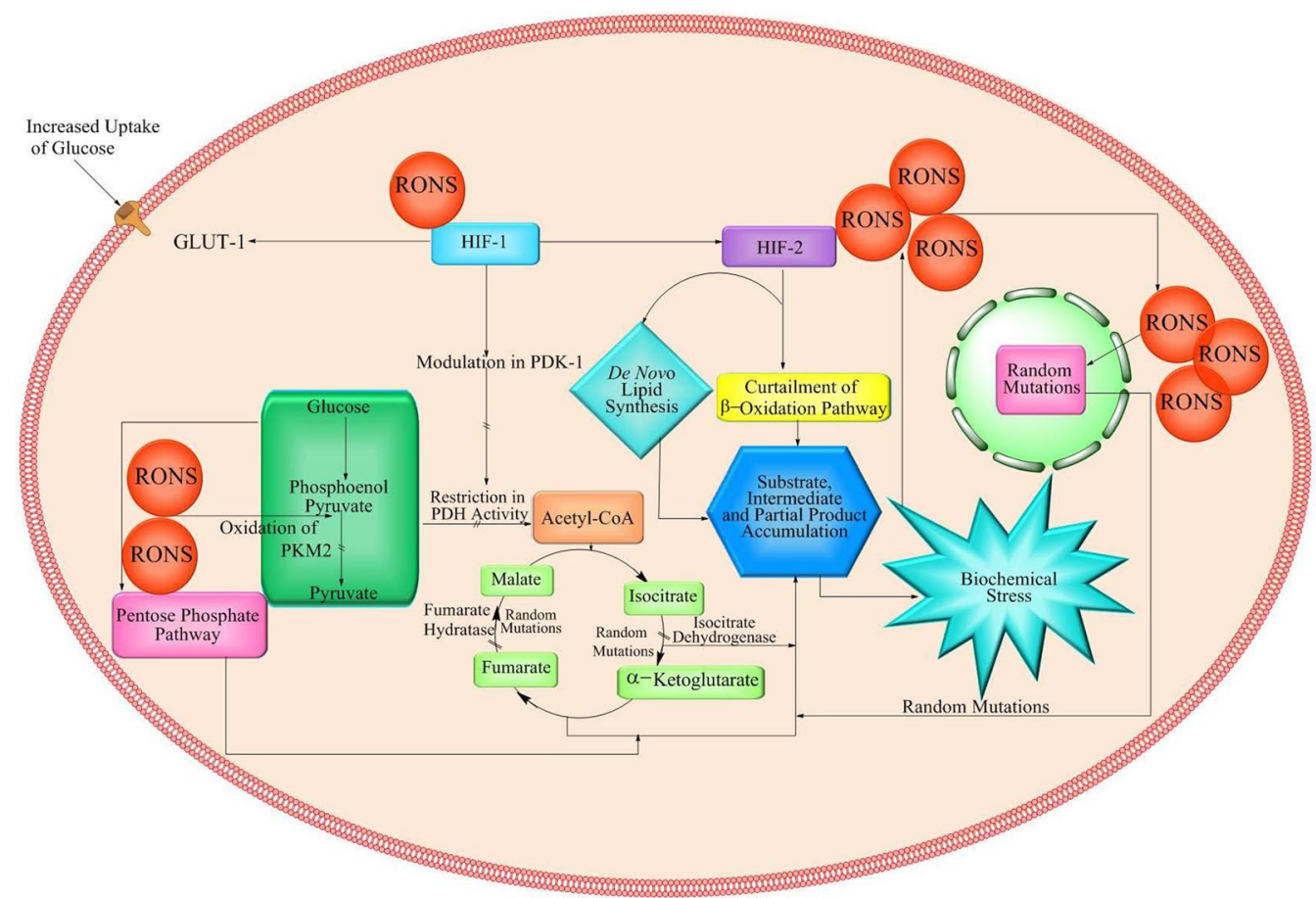

Fig. 3 Phase II (The Nexus model): RONS and their interference leading to development of biochemical stress i.e. The Nexus 
react with nearby nucleotides, leading to aberrant methylation-induced gene silencing [88]. All these reports confirm that biochemical stress as the Nexus creates necessity and acts as a source code for epigenetic makeup during cellular transition in cancer.

\section{Cancer epigenetics}

Cellular transition further continues when these epigenetic abnormalities lead to disturbances in the cellular genetic makeup [89]. Epidermal growth factor receptor (EGFR) is one such example which governs the signaling pathways involved in the regulation of growth, metabolism, differentiation and apoptosis under stressed conditions through its tyrosine kinase (TK) activity. Mutation in the epidermal growth factor receptor-tyrosine kinase (EGFR-TK) domain in ovarian cancer has resulted in the over production of EGFR $[90,91]$. This overproduction in turn alters the activity of DNA methyltransferase, an enzyme which is responsible for DNA methylation [92-95]. DNA methylation is the most widely investigated epigenetic modulation in cancer. In normal conditions, it regulates gene expression and inactivation. The methyl group covalently attaches to the cytosine residues in the CpG dinucleotides [96, 97]. These CpG sites are not randomly distributed in the genome; instead the $\mathrm{CpG}$ rich regions are known as $\mathrm{CpG}$ islands and they generally cluster at the $5^{\prime}$ end of the regulatory region (generally the promoter region) of many genes $[89,96]$. These islands are not methylated in normal cells [98]. Hypermethylation of $\mathrm{CpG}$ islands in the promoter region of tumor suppressor genes is a major event in the origin of many types of cancer. Hypermethylation of promoter region of CpG-islands out-turns into complete or partial loss of genes involved in the normal functioning of cell including those involved in cell cycle, DNA repair, and metabolism of carcinogens, cell to cell interaction, apoptosis and angiogenesis [96]. The methylated CpG islands are not capable of initiating transcription and hence there is an altered gene function. Thus, hypermethylation at the promoter region favors the mechanism of mutation and helps to accelerate random mutations during cellular transformation [99]. As a result of hypermethylation in the promoter region, the tumor suppressor gene $\mathrm{p} 16$, which regulates the proliferation rate of the cell is not transcribed and thus gets inactivated. Inactivation of gene p16 leads to the uncontrolled proliferation of tumor cells [100]. Mutations take place in the mTOR (mammalian Target of Rapamycin) signaling pathway due to the loss of tumor suppressors or activation of oncogenes promotes tumor growth and survival. Activation of mTOR pathway is also reported to take place under stressed conditions such as nutrient deprivation [10,101]. Reports which have identified hypermethylation of many genes in various cancers are collectively presented in Table 1.

Apart from DNA methylation, there are other covalent modifications like histone modifications which control gene activity and play a major role in cancer development [100]. Post translational histone modifications have direct influence on chromatin structure and function. It usually results in rewired gene regulation; it includes histone deacetylation and histone acetylation [102]. Histone acetylation mediated by histone acetyltransferase (HAT) and histone deacetylation mediated by histone deacetylase (HDAC) plays a crucial role in gene expression and silencing. HDAC is found to be related with tumor development as it induces transcriptional inactivation $[10,103]$. The deacetylation of lysine residues of histone 3 and histone 4 largely increases the ionic contact between positively charged DNA packaging proteins (histone) and negatively charged DNA which condenses the chromatin and makes transcriptional gene inert $[104,105]$.

Transcriptional blockage of tumor suppressor gene by upregulation or bizarre recruitment of HDACs to their promoter site is a common feature for emergence and tumor development [106]. The acetylation status of histones $\mathrm{H} 3$ and $\mathrm{H} 4$ seem to largely dictate the fate of chromatin assembly, transcription, and gene expression [107, 108]. Histone acetylation is governed by the opposing activities of HATs and HDACs $[109,110]$. Thus the loss of normal functioning of gene opens a divergent pathway to escape early senescence, leading to genetic changes, which results in the escape of cancer cells from apoptosis [111].

\section{Table 1 Hypermethylation of various genes investigated in different types of cancers}

\begin{tabular}{lll}
\hline S. N. & Site of hypermethylation & Type of cancer \\
\hline 1 & Glutathione S transferase gene (GSTPI, also known as GST3) & Prostate and breast cancer [91] \\
2 & Promoter region of Liver Kinase B1 (LKB1) & Papillary breast cancer [92] \\
3 & Promoter region of cyclin-dependent Kinase inhibitor p15INK4B & Leukemia and glioma [93] \\
4 & Promoter CpG island of the O6-MGMT gene & Brain, colon and lung cancer [94] \\
5 & CpG island of death-associated protein Kinase DAP-Kinase & Lymphomas [95] \\
\hline
\end{tabular}


The above evidences conclude that biochemical stress (the Nexus) induces epigenetic events which helps cell to rule out normal gene expression and create a demand of improved genetic makeup which could off load the prolonged biochemical stress. Once these epigenetic alterations mediate genetic changes, the last step in the phase of cellular transition of selection, adaptation and evolution comes into play. These events are depicted in Fig. 4.

\section{Cancer genetics}

The loss of functional genes by epigenetic silencing has been shown to mediate genetic mutations leading to the development of tumor cells [112]. The epigenetic alterations initiate a cascade of reactions which may not only shut a single pathway but also affect other important signaling pathways. Further these abnormalities conduct linked distortion of metabolic pathways to promote tumorigenesis [113]. Loss of intercellular signals resulted from biochemical stress acts as a catalyst in genetic evolution. Initially, the genetic mutations are random and may occur as a genetic response to epigenetic codes developed from prolonged biochemical stress. Progressively, mutations which help the cell to overcome residual content, promote the errant growth and help to relieve the cellular stress are selected naturally. Stress inducible mutagenesis mechanism can potentially accelerate adaptive evolution of cancerous cells. A few examples supporting the selective adaptation and evolution have been collected here.
In many colon cancers, a mutation that inactivates the tumor-suppressor gene called APC (adenomatous polyposis coli) is the first or at least a very early, step in cancer progression. APC mutations can be detected in small benign polyps at the same high frequency as in large malignant tumors, suggesting that they occur early in the process. The loss of APC activity gives the affected cell a growth advantage, allowing it to form a colony of cells that divide more rapidly than they die. The increased proliferation leads to the growth of a polyp [114], pointing out the possibility of the fact that a particular mutation gets selected only when proved beneficial in evolution inside the cell. Once cells lose their ability to repair these replication errors, mutations can accumulate in many genes, including tumor suppressor genes and oncogenes. Patients with this genetic defect develop one or two tumors that then progress rapidly to a full-blown cancer [115].

The breast cancer genes (BRCA1 and BRCA2) are found to mediate DNA damage control in cells and regulation of transcription. Mutations in these two genes are profoundly associated with occurrence of breast cancer and ovarian cancer. It has been evaluated and confirmed in vitro that absence or mutations in these genes result in uncontrolled proliferation and tumor development [116]. Similarly, mutations in epidermal growth factor receptor (EGFR) gene have been identified in lung adenocarcinomas helping cancer cells in proliferation, migration and metastasis [117]. Many other gene mutations are strongly

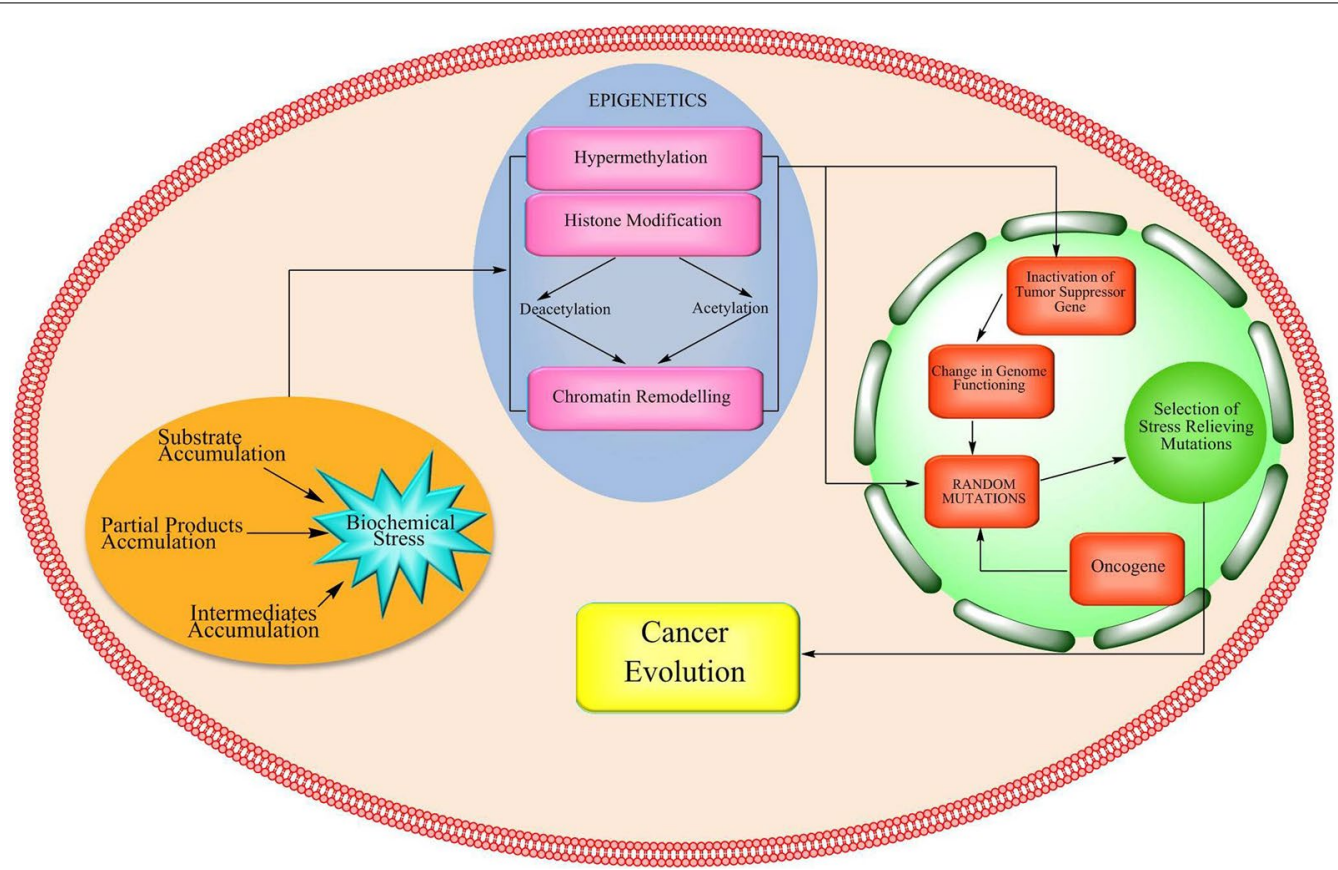

Fig. 4 Phase III-Biochemical stress (The Nexus) to epigenetics and genetics in cancer evolution 
linked to numerous cancers; these mutations support common features of cancer cells. The altered functions of these mutated genes in cancer appear to be beneficial in evolution. The cancer evolution has a purpose where selective mutations act as soldiers to fight against cellular biochemical stress via altering, accelerating or rewiring cellular processes so as to reduce nutritional metabolite overload and accumulation resulted from cellular impeders.

\section{Results and discussion}

The 'Nexus' model connects primary cancer-causing factors, cellular biochemistry, epigenetics and genetics in cancer. By naming the epicenter of all such events as the 'Nexus', we have tried to justify the purpose on which a healthy cell under stress persuades to transform to its cancer phenotype. This model may add a new dimension and perspective to cancer research where to understand the exact cause of cancer; we must first discover the purpose of evolution. The questions to be addressed should be, why cells choose to evolve or transform to cancerous form and in what context the evolution is beneficial to the cell. The Nexus model would lead to finding new drug targets which are directly or indirectly involved in accumulation of metabolites and add or reduce biochemical stress in a cell. The unfathomable queries linked to cancer may be answered using the Nexus model.

This model links primary causes to cancer development but not directly. It validates usual enquiry of why all people exposed to primary causes of cancers (e.g. alcohol, tobacco) do not develop cancer whereas individuals who are not at all exposed to any one of the primary causes show linked cancer incidences. There could be ancillary possible reasons which may cause biochemical stress other than primary inducers in linked tissues. Over a past few centuries, many theories on cancer development have been proposed. The Nexus model encompasses and validates such major preexistent theories viz. trauma theory, infectious disease theory, somatic mutation theory, tissue organization field theory and epigenetic theory. These theories and their indicated causes could be linked to biochemical stress in a way or other way around.

\section{Conclusions}

Common features of cancer cells imply towards a common underlying cause of cancer irrespective of their origin and pathophysiology. Primary causes are not directly linked to cancer evolution; rather, they end up with the production of cellular impeders (RONS). Perpetuated biochemical stress resulted from the accumulation of substrates, intermediates and partial products acts as 'The Nexus'. The Nexus is the end product of primary inducers and cellular impeders. It develops altered cellular environment which acts as a key ingredient of cancer epigenetics. The codes retrieved from 'The Nexus' are processed by epigenetics and are finally forwarded to cancer genetics. At first, the mutations are random but become selective when they help the cell to overcome the biochemical stress. Selective mutations are found to outlaw normal cellular processes, promote accelerated and aberrant growth, and rewire metabolic pathways and many other common benefits to negotiate with extended biochemical stress. The Nexus may act as the switch and the common cause in cancer evolution.

\section{Abbreviations \\ RONS: reactive oxygen and nitrogen species; ROS: reactive oxygen species; RNS: reactive nitrogen species; BMl: body mass index; TNF-a: tumor necrosis factor-a; IL-6: interleukin-6; UVA: ultra violet A; ER: endoplasmic reticulum; Neu5Gc: N-glycolylneuraminic acid; CagA: cytotoxin-associated gene A; HPV: human papillomavirus; PKM2: pyruvate kinase monomer 2; PEP: phosphoenol pyruvate; HIF-1: hypoxia inducible factor-1; GLUT-1: glucose transporter-1; PDK1: pyruvate dehydrogenase kinase 1; PDH: pyruvate dehydrogenase; TCA: tricarboxylic acid cycle; ETC: electron transport chain; PPP: pentose phosphate pathway; HIF-2: hypoxia inducible factor-2; VHL: Von Hippel-Lindau gene; FASN: fatty acid synthase; IDH: isocitrate dehydrogenase; 2-HG: 2-hydroxy- glutarate; FH: fumarate hydratase; GSH: glutathione; UFR: unfolded protein response; BiP: binding immunoglobulin protein; GRP78: 78 kDa glucose-reg- ulated protein; AIF: apoptosis inducing factor; EGFR: epidermal growth factor receptor; EGFR-TK: epidermal growth factor receptor-tyrosine kinase domain; mTOR: mammalian target of rapamycin; PI3K: phosphatidylinositol-4,5-bi- sphosphate 3-kinase; AMPK: 5' AMP-activated protein kinase; HAT: histone acetyltransfarase; HDAC: histone deacetylase; APC: adenomatous polyposis coli; BRCA1: breast cancer 1; BRCA2: breast cancer 2.}

\section{Authors' contributions}

The original concept development and compilation are done by corresponding author, MY. PC has played a pivotal role in the development of manuscript. MM and JK have developed phase I and phase II of Nexus model. AS completed and compiled phase III. ST wrote background and edited manuscript time to time. NC actively designed diagrams. All other authors have supported the manuscript equally. All authors read and approved the final manuscript.

\section{Author details \\ 1 Department of Pharmaceutical Sciences, Softvision College and Research Institute, Vijaynagar, Indore, MP 452010, India. ${ }^{2}$ Department of Pharmaceuti- cal Sciences, College of Pharmacy, Western University of Health Sciences, Pomona, CA 91766, USA.}

\section{Acknowledgements}

Our special thanks to Prof. Emeritus Shridhar Patil for his continuous guidance and critical views which he has offered during development of present work. We pay sincere gratitude to Mr. Neeraj Desai, Director and Founder, Softvision Research Institute who continuously motivated and fueled us time to time. We also acknowledge the supporting role of Sanket Vaidya and Anudeep Sharma in the development of present manuscript.

\section{Competing interests}

The authors declare that they have no competing interests.

Availability of data and materials

Not applicable.

\section{Consent for publication}

Corresponding author has full consent from all co-authors, affiliated department and institute. 


\section{Ethics approval and consent to participate}

Present work does not require any ethical approval and consent as it is completely free from the studies of concern thereby.

\section{Funding}

Present work is not funded by any funding agency in any form.

\section{Publisher's Note}

Springer Nature remains neutral with regard to jurisdictional claims in published maps and institutional affiliations.

Received: 11 April 2018 Accepted: 1 August 2018

Published online: 07 August 2018

\section{References}

1. Trosko JE, Chang CC. Stem cell theory of carcinogenesis. Toxicol Lett. 1989;49:283-95

2. Pervan V, Cohen L, Jaftha T. Oncology for health-care professionals. Claremont: Juta and Company Ltd; 1995.

3. Tai MH, Chang CC, Kiupel M, Webster JD, Olson LK, Trosko JE. Oct4 expression in adult human stem cells: evidence in support of the stem cell theory of carcinogenesis. Carcinogenesis. 2005;26:495-502.

4. Tracey KJ. Physiology and immunology of the cholinergic antiinflammatory pathway. J Clin Invest. 2007;117:289.

5. Jaffe LF. Epigenetic theories of cancer initiation. Adv Cancer Res. 2003;90:209-30.

6. Feinberg AP. Genomic imprinting and gene activation in cancer. Nat Genet. 1993;4:110-3.

7. Sonnenschein C, Soto AM. Somatic mutation theory of carcinogenesis: why it should be dropped and replaced. Mol Carcinog. 2000;29:205-11.

8. Sonnenschein C, Soto AM. Theories of carcinogenesis: an emerging perspective. Semin Cancer Biol. 2008;18:372-7.

9. Soto AM, Sonnenschein C. The tissue organization field theory of cancer: a testable replacement for the somatic mutation theory. BioEssays. 2011;33:332-40.

10. Hanahan D, Weinberg RA. Hallmarks of cancer: the next generation. Cell. 2011;144:646-74

11. Zink D, Fischer AH, Nickerson JA. Nuclear structure in cancer cells. Nat Rev Cancer. 2004;4:677-87.

12. Coman DR. Decreased mutual adhesiveness, a property of cells from squamous cell carcinomas. Cancer Res. 1944;4:625-9.

13. Casás-Selves M, DeGregori J. How cancer shapes evolution, and how evolution shapes cancer. Evolution. 2011;4:624-34.

14. Foyer $\mathrm{CH}$, Harbinson J. Oxygen metabolism and the regulation of photosynthetic electron transport. In: Foyer $\mathrm{CH}$, Mullineaux P, editors. Causes of photooxidative stresses and amelioration of defense systems in plants. Boca Raton: CRC Press; 1994. p. 1-42.

15. Wagner D, Przybyla D, Op den Camp R, Kim C, Landgraf F, Lee KP, et al. The genetic basis of singlet oxygen-induced stress response of Arabidopsis thaliana. Science. 2004;306:1183-5.

16. Kasai $\mathrm{H}$. Analysis of a form of oxidative DNA damage, 8-hydroxy-2'deoxyguanosine, as a marker of cellular oxidative stress during carcinogenesis. Mutat Res. 1997;387:147-63.

17. Zhao Y, Hu X, Liu Y, Dong S, Wen Z, He W, et al. ROS signaling under metabolic stress: cross-talk between AMPK and AKT pathway. Mol Cancer. 2017;16:79.

18. Maley CC, Forrest S. Exploring the relationship between neutral and selective mutations in cancer. Artif Life. 2000;6:325-45.

19. Bignell GR, Greenman CD, Davies H, Butler AP, Edkins S, Andrews JM, et al. Signatures of mutation and selection in the cancer genome. Nature. 2010;463:893-8

20. Gatto F, Schulze A, Nielsen J. Systematic analysis reveals that cancer mutations converge on deregulated metabolism of arachidonate and xenobiotics. Cell Rep. 2016:16:878-95.

21. Dang CV. Links between metabolism and cancer. Genes Dev. 2012;26:877-90

22. Hsu PP, Sabatini DM. Cancer cell metabolism: Warburg and beyond. Cell. 2008;134:703-7.
23. Locasale JW, Cantley LC. Altered metabolism in cancer. BMC Biol. 2010;8:88.

24. Baenke F, Peck B, Miess H, Schulze A. Hooked on fat: the role of lipid synthesis in cancer metabolism and tumour development. Dis Models Mech. 2013:6:1353-63.

25. Currie E, Schulze A, Zechner R, Walther Tobias C, Farese Robert V. Cellular fatty acid metabolism and cancer. Cell Metab. 2013;18:153-61.

26. Gordan JD, Thompson CB, Simon MC. HIF and c-Myc: sibling rivals for control of cancer cell metabolism and proliferation. Cancer Cell. 2007:12:108-13.

27. Jain M, Nilsson R, Sharma S, Madhusudhan N, Kitami T, Souza AL, et al. Metabolite profiling identifies a key role for glycine in rapid cancer cell proliferation. Science. 2012;336:1040-4.

28. Valko M, Rhodes CJ, Moncol J, Izakovic M, Mazur M. Free radicals, metals and antioxidants in oxidative stress-induced cancer. Chem Biol Interact. 2006;160:1-40.

29. Azad N, Rojanasakul Y, Vallyathan V. Inflammation and lung cancer: roles of reactive oxygen/nitrogen species. J Toxicol Environ Health B. 2008;11:1-15

30. Wiseman $\mathrm{H}$, Halliwell B. Damage to DNA by reactive oxygen and nitrogen species: role in inflammatory disease and progression to cancer. Biochem J. 1996:313:17.

31. Valavanidis A, Vlachogianni T, Fiotakis K. Tobacco smoke: involvement of reactive oxygen species and stable free radicals in mechanisms of oxidative damage, carcinogenesis and synergistic effects with other respirable particles. Int J Environ Res Public Health. 2009;6:445-62.

32. Trachootham D, Alexandre J, Huang P. Targeting cancer cells by ROSmediated mechanisms: a radical therapeutic approach? Nat Rev Drug Discov. 2009:8:579-91.

33. National Institute of Cancer. Obesity and Cancer. https://www.cance r.gov/aboutcancer/causesprevention/risk/obesity/obesity-fact-sheet. Accessed Sept 2017

34. Furukawa S, Fujita T, Shimabukuro M, Iwaki M, Yamada Y, Nakajima Y, et al. Increased oxidative stress in obesity and its impact on metabolic syndrome. J Clin Invest. 2004;114:1752-61.

35. Le Lay S, Simard G, Martinez MC, Andriantsitohaina R. Oxidative stress and metabolic pathologies: from an adipocentric point of view. Oxid Med Cell Longev. 2014:2014:908539.

36. Tyrrell RM. Ultraviolet radiation and free radical damage to skin. Biochem Soc Symp. 1995:61:47-53.

37. Bossi O, Gartsbein M, Leitges M, Kuroki T, Grossman S, Tennenbaum T. UV irradiation increases ROS production via PKCdelta signaling in primary murine fibroblasts. J Cell Biochem. 2008;105:194-207.

38. Schmeltz I, Hoffmann D. Nitrogen-containing compounds in tobacco and tobacco smoke. Chem Rev. 1977:77:295-311.

39. Lijinsky W, Keefer L, Conrad E, Van de Bogart R. Nitrosation of tertiary amines and some biologic implications. J Natl Cancer Inst. 1972;49:1239-49.

40. Smith PA, Loeppky RN. Nitrosative cleavage of tertiary amines. J Am Chem Soc. 1967;89:1147-57.

41. Ryter SW, Kim HP, Hoetzel A, Park JW, Nakahira K, Wang X, Choi AM. Mechanisms of cell death in oxidative stress. Antioxid Redox Signal. 2007:9:49-89.

42. Church DF, Pryor WA. Free-radical chemistry of cigarette smoke and its toxicological implications. Environ Health Perspect. 1985:64:111-26.

43. Lambeth JD. Nox enzymes, ROS, and chronic disease: an example of antagonistic pleiotropy. Free Radic Biol Med. 2007:43:332-47.

44. Pryor WA, Stone K. Oxidants in cigarette smoke. Radicals, hydrogen peroxide, peroxynitrate, and peroxynitrite. Ann N Y Acad Sci. 1993:686:12-27.

45. McElvaney NG, Greene CM. Mechanisms of protein misfolding in conformational lung diseases. Curr Mol Med. 2012;12:850-9.

46. Jorgensen E, Stinson A, Shan L, Yang J, Gietl D, Albino AP. Cigarette smoke induces endoplasmic reticulum stress and the unfolded protein response in normal and malignant human lung cells. BMC Cancer. 2008:8:229.

47. Agarwal DP. Genetic polymorphisms of alcohol metabolizing enzymes. Pathol Biol. 2001:49:703-9.

48. Parkin DM. Cancers attributable to consumption of alcohol in the UK in 2010. Br J Cancer. 2011;105:14-8. 
49. Simeonova PP, Luster MI. Iron and reactive oxygen species in the asbestos-induced tumor necrosis factor-alpha response from alveolar macrophages. Am J Respir Cell Mol Biol. 1995;12:676-83.

50. Tchounwou PB, Yedjou CG, Patlolla AK, Sutton DJ. Heavy metal toxicity and the environment. EXS. 2012;101:133-64.

51. Jannaschk D, Burgos M, Centerlles JJ, Ovadi J, Cascante M. Application of metabolic control analysis to the study of toxic effects of copper in muscle glycolysis. FEBS Lett. 1999;445:144-8.

52. Vernhet L, Seite MP, Allain N, Guillouzo A, Fardel O. Arsenic induces expression of the multidrug resistance-associated protein 2 (MRP2) gene in primary rat and human hepatocytes. J Pharmacol Exp Ther. 2001;298:234-9.

53. Samraj AN, Pearce OM, Laubli H, Crittenden AN, Bergfeld AK, Banda K, et al. A red meat-derived glycan promotes inflammation and cancer progression. Proc Natl Acad Sci USA. 2015;112:542-7.

54. Costa AP, de Paula RC, Carvalho GF, Araujo JP, Andrade JM, de Almeida $\mathrm{OL}$, et al. High sodium intake adversely affects oxidative-inflammatory response, cardiac remodelling and mortality after myocardial infarction. Atherosclerosis. 2012;222:284-91.

55. Loh JT, Torres VJ, Cover TL. Regulation of Helicobacter pylori cagA expression in response to salt. Cancer Res. 2007;67:4709-15.

56. Williams VM, Filippova M, Filippov V, Payne KJ, Duerksen-Hughes P Human papillomavirus type $16 \mathrm{E}^{*}$ induces oxidative stress and DNA damage. J Virol. 2014;88:6751-61.

57. Williams VM, Filippova M, Soto U, Duerksen-Hughes PJ. HPV-DNA integration and carcinogenesis: putative roles for inflammation and oxidative stress. Future Virol. 2011:6:45-57.

58. Radak Z, Marton O, Nagy E, Koltai E, Goto S. The complex role of physical exercise and reactive oxygen species on brain. J Sport Health Sci. 2013;2:87-93

59. Halliwell B. Oxidative stress and cancer: have we moved forward? Biochem J. 2007:401:1-11.

60. Schumacker PT. Reactive oxygen species in cancer: a dance with the devil. Cancer Cell. 2015;27:156-7.

61. Ebert BL, Firth JD, Ratcliffe PJ. Hypoxia and mitochondrial inhibitors regulate expression of glucose transporter-1 via distinct Cis-acting sequences. J Biol Chem. 1995;270:29083-9.

62. Kim JW, Tchernyshyov I, Semenza GL, Dang CV. HIF-1-mediated expression of pyruvate dehydrogenase kinase: a metabolic switch required for cellular adaptation to hypoxia. Cell Metab. 2006;3:177-85.

63. Yamamoto T, Takano N, Ishiwata K, Ohmura M, Nagahata Y, Matsuura $\mathrm{T}$, et al. Reduced methylation of PFKFB3 in cancer cells shunts glucose towards the pentose phosphate pathway. Nat Commun. 2014;5:3480.

64. Semba H, Takeda N, Isagawa T, Sugiura Y, Honda K, Wake M, et al. HIF1alpha-PDK1 axis-induced active glycolysis plays an essential role in macrophage migratory capacity. Nat Commun. 2016;7:11635.

65. Wellen KE, Thompson CB. Cellular metabolic stress: considering how cells respond to nutrient excess. Mol Cell. 2010;40:323-32.

66. Ward PS, Thompson CB. Metabolic reprogramming: a cancer hallmark even warburg did not anticipate. Cancer Cell. 2012;21:297-308.

67. Hamanaka RB, Chandel NS. Warburg effect and redox balance. Science. 2011;334:1219-20.

68. Gimm T, Wiese M, Teschemacher B, Deggerich A, Schodel J, Knaup $K X$, et al. Hypoxia-inducible protein 2 is a novel lipid droplet protein and a specific target gene of hypoxia-inducible factor-1. FASEB J. 2010;24:4443-58.

69. Rankin EB, Rha J, Selak MA, Unger TL, Keith B, Liu Q, et al. Hypoxiainducible factor 2 regulates hepatic lipid metabolism. Mol Cell Biol. 2009:29:4527-38.

70. Rezende RB, Drachenberg CB, Kumar D, Blanchaert R, Ord RA, loffe OB, et al. Differential diagnosis between monomorphic clear cell adenocarcinoma of salivary glands and renal (clear) cell carcinoma. Am J Surg Pathol. 1999;23:1532.

71. Furuta E, Pai SK, Zhan R, Bandyopadhyay S, Watabe M, Mo Y-Y, et al. Fatty acid synthase gene is up-regulated by hypoxia via activation of Akt and sterol regulatory element binding protein-1. Cancer Res. 2008;68:1003-11.

72. Yoshii Y, Furukawa T, Yoshii H, Mori T, Kiyono Y, Waki A, et al. Cytosolic acetyl-CoA synthetase affected tumor cell survival under hypoxia: the possible function in tumor acetyl-CoA/acetate metabolism. Cancer Sci. 2009:100:821-7.
73. Hsie AW, Recio L, Katz DS, Lee CQ, Wagner M, Schenley RL. Evidence for reactive oxygen species inducing mutations in mammalian cells. Proc Natl Acad Sci USA. 1986:83:9616-20.

74. Cairns RA, MakTW. Oncogenic isocitrate dehydrogenase mutations: mechanisms, models, and clinical opportunities. Cancer Discov. 2013;3:730-41.

75. Figueroa ME, Abdel-Wahab O, Lu C, Ward PS, Patel J, Shih A, et al. Leukemic IDH1 and IDH2 mutations result in a hypermethylation phenotype, disrupt TET2 function, and impair hematopoietic differentiation. Cancer Cell. 2010;18:553-67.

76. Amary MF, Damato S, Halai D, Eskandarpour M, Berisha F, Bonar F, et al. Ollier disease and Maffucci syndrome are caused by somatic mosaic mutations of IDH1 and IDH2. Nat Genet. 2011;43:1262-5.

77. Wang P, Dong Q, Zhang C, Kuan PF, Liu Y, Jeck WR, et al. Mutations in isocitrate dehydrogenase 1 and 2 occur frequently in intrahepatic cholangiocarcinomas and share hypermethylation targets with glioblastomas. Oncogene. 2013;32:3091-100.

78. Sudarshan S, Sourbier C, Kong HS, Block K, Valera Romero VA, Yang Y, et al. Fumarate hydratase deficiency in renal cancer induces glycolytic addiction and hypoxia-inducible transcription factor 1alpha stabilization by glucose-dependent generation of reactive oxygen species. Mol Cell Biol. 2009;29:4080-90.

79. Sullivan LB, Martinez-Garcia E, Nguyen H, Mullen AR, Dufour E, Sudarshan S, et al. The proto-oncometabolite fumarate binds glutathione to amplify ROS-dependent signaling. Mol Cell. 2013;51:236-48.

80. Linehan WM, Rouault TA. Molecular pathways: fumarate hydratase-deficient kidney cancer: targeting the Warburg effect in cancer. Clin Cancer Res. 2013;19:3345-52

81. Jones PA, Baylin SB. The epigenomics of cancer. Cell. 2007;128:683-92.

82. Ropero S, Esteller M. The role of histone deacetylases (HDACs) in human cancer. Mol Oncol. 2007:1:19-25.

83. Wang M, Wey S, Zhang Y, Ye R, Lee AS. Role of the unfolded protein response regulator GRP78/BiP in development, cancer, and neurological disorders. Antioxid Redox Signal. 2009;11:2307-16.

84. Ron D, Walter P. Signal integration in the endoplasmic reticulum unfolded protein response. Nat Rev Mol Cell Biol. 2007;8:519-29.

85. Fulda S, Gorman AM, Hori O, Samali A. Cellular stress responses: cell survival and cell death. Int J Cell Biol. 2010;2010:214074.

86. Valko M, Izakovic M, Mazur M, Rhodes CJ, Telser J. Role of oxygen radicals in DNA damage and cancer incidence. Mol Cell Biochem. 2004;266:37-56

87. Franco R, Schoneveld O, Georgakilas AG, Panayiotidis MI. Oxidative stress, DNA methylation and carcinogenesis. Cancer Lett. 2008:266:6-11.

88. Kawai K, Li YS, Song MF, Kasai H. DNA methylation by dimethyl sulfoxide and methionine sulfoxide triggered by hydroxyl radical and implications for epigenetic modifications. Bioorg Med Chem Lett. 2010;20:260-5.

89. Herman JG, Baylin SB. Gene silencing in cancer in association with promoter hypermethylation. N Engl J Med. 2003;349:2042-54.

90. Shigematsu H, Lin L, Takahashi T, Nomura M, Suzuki M, Wistuba II, et al. Clinical and biological features associated with epidermal growth factor receptor gene mutations in lung cancers. J Natl Cancer Inst. 2005;97:339-46.

91. Pardinas JR, Xiao L, Zhang J, Li K. Re: clinical and biological features associated with epidermal growth factor receptor gene mutations in lung cancers. J Natl Cancer Inst. 2006;98:362-3.

92. Ono M, Kuwano M. Molecular mechanisms of epidermal growth factor receptor (EGFR) activation and response to gefitinib and other EGFRtargeting drugs. Clin cancer Res. 2006;12:7242-51.

93. Samudio-Ruiz SL, Hudson LG. Increased DNA methyltransferase activity and DNA methylation following epidermal growth factor stimulation in ovarian cancer cells. Epigenetics. 2012;7:216-24.

94. Vlahovic G, Crawford J. Activation of tyrosine kinases in cancer. Oncologist. 2003;8:531-8.

95. Paul MK, Mukhopadhyay AK. Tyrosine kinase-role and significance in cancer. Int J Med Sci. 2004;1:101-15.

96. Kulis M, Esteller M. DNA methylation and cancer. Adv Genet. 2010;70:27-56 
97. Kulis M, Queiros AC, Beekman R, Martin-Subero Jl. Intragenic DNA methylation in transcriptional regulation, normal differentiation and cancer. Biochem Biophys Acta. 2013;1829:1161-74.

98. Cody DT 2nd, Huang Y, Darby CJ, Johnson GK, Domann FE. Differential DNA methylation of the p16 INK4A/CDKN2A promoter in human oral cancer cells and normal human oral keratinocytes. Oral Oncol. 1999;35:516-22.

99. Herman JG, Baylin SB. Promoter-region hypermethylation and gene silencing in human cancer. Curr Top Microbiol Immunol. 2000;249:35-54

100. Esteller M. Cancer epigenomics: DNA methylomes and histone-modification maps. Nat Rev Genet. 2007;8:286-98.

101. Sato T, Nakashima A, Guo L, Coffman K, Tamanoi F. Single amino-acid changes that confer constitutive activation of mTOR are discovered in human cancer. Oncogene. 2010;29:2746.

102. Cohen I, Poreba E, Kamieniarz K, Schneider R. Histone modifiers in cancer: friends or foes? Genes Cancer. 2011;2:631-47.

103. Faivre S, Kroemer G, Raymond E. Current development of mTOR inhibitors as anticancer agents. Nat Rev Drug Discov. 2006;5:671-88.

104. Ehrenhofer-Murray AE. Chromatin dynamics at DNA replication, transcription and repair. Eur J Biochem. 2004;271:2335-49.

105. Berger SL. The complex language of chromatin regulation during transcription. Nature. 2007;447:407-12.

106. Kim MS, Kwon HJ, You ML, Baek JH, Jang J-E, Sae-Won L, et al. Histone deacetylases induce angiogenesis by negative regulation of tumor suppressor genes. Nat Med. 2001;7:437.
107. Shogren-Knaak M, Ishii H, Sun JM, Pazin MJ, Davie JR, Peterson CL. Histone H4-K16 acetylation controls chromatin structure and protein interactions. Science. 2006;311:844-7.

108. Grunstein M. Histone acetylation in chromatin structure and transcription. Nature. 1997:389:349-52

109. Bannister AJ, Kouzarides T. Regulation of chromatin by histone modifications. Cell Res. 2011;21:381-95.

110. Wang Z, Qin G, Zhao TC. Histone deacetylase 4 (HDAC4): mechanism of regulations and biological functions. Epigenomics. 2014;6:139-50.

111. Baylin SB, Herman JG. DNA hypermethylation in tumorigenesis: epigenetics joins genetics. Trends Genet. 2000;16:168-74.

112. Sharma S, Kelly TK, Jones PA. Epigenetics in cancer. Carcinogenesis. 2010:31:27-36.

113. Phang JM, Liu W, Hancock C. Bridging epigenetics and metabolism: role of non-essential amino acids. Epigenetics. 2013;8:231-6.

114. Baylin SB, Ohm JE. Epigenetic gene silencing in cancer-a mechanism for early oncogenic pathway addiction? Nat Rev Cancer. 2006;6:107-16.

115. Jones PA, Baylin SB. The fundamental role of epigenetic events in cancer. Nat Rev Genet. 2002;3:415-28.

116. Welcsh PL, King MC. BRCA1 and BRCA2 and the genetics of breast and ovarian cancer. Hum Mol Genet. 2001;10:705-13.

117. Siegelin MD, Borczuk AC. Epidermal growth factor receptor mutations in lung adenocarcinoma. Lab Invest. 2014;94:129-37.
Ready to submit your research? Choose BMC and benefit from:

- fast, convenient online submission

- thorough peer review by experienced researchers in your field

- rapid publication on acceptance

- support for research data, including large and complex data types

- gold Open Access which fosters wider collaboration and increased citations

- maximum visibility for your research: over 100M website views per year

At BMC, research is always in progress.

Learn more biomedcentral.com/submissions 